\title{
COMUNICAÇÃO
}

\section{CICLO INTRACELULAR DO TRYPANOSOMA CRUZI E SUA IMPORTÂNCIA NA PATOGÊNESE DA DOENÇA DE CHAGAS}

\author{
Washington Luiz Tafuri, Egler Chiari e Pedro Raso
}

Até o momento, são desconhecidos os mecanismos mediante os quais o $T$. cruzi abandona o sangue, atravessa a parede capilar e entra nas células . Também, são pouco sabidos os mecanismos pelos quais cumpre o caminho inverso: do interior das células para a corrente circulatória. Experiências in vitro ${ }^{5}$ parecem mostrar que a penetração das formas epimastigotas e amastigotas nas células se faz por endocitose, e que duas horas após a penetração os parasitas seriam envolvidos por uma membrana, que os separa dos orgânulos citoplasmáticos. Posteriormente, essa membrana envoltória se fragmentaria e os parasitas ficariam livres no citoplasma celular.

É sabido que, in vitro, logo após sua entrada nas células as formas tripomastigotas se transformam em amastigotas e que estas se multiplicam, por divisão binária, a cada 12 horas $^{4}$. Dependendo do tamanho das células parasitadas, cada uma delas pode conter um máximo de 500 amastigotas; ou seja, segundo Dvorak ${ }^{3}$, ocorrem nove gerações antes do rompimento da célula e da liberação dos parasitas.

A presença ou não de formas epimastigotas típicas na célula hospedeira de vertebrados é controvertida. Tudo parece indicar, porém, que a transformação dos amastigotas se inicia imediatamente antes de ser atingido o ponto crítico para o rompimento da célula, quando esta se acha cheia de parasitos. A transformação seria muito rápida. Seria esse, possivelmente, o motivo, segundo a opinião de Elkeless ${ }^{2}$, e a nossa, pelo qual a metamorfose e a presença intracelular de tripomastigotas são detectados tão raramente. De fato, a revisão de nossas fotografias, arquivadas desde $1964 \mathrm{e}$ referentes à fase aguda de infecção experimental em camundongos, confirmou que as células parasitadas contendo ninhos de amastigotas não mostram sinais de ruptura (da membrana plasmática)

Departamento de Biologia do ICEB da UFOP e Departamento de Anatomia Patológica da UFMG. Trabalho financiado pelo CNPq e FINEp.

Recebido para publicação em 13/4/1983. e não liberam parasitas. $r$ is amastigotas integras induzem lise do citoplasma rue as circunda, formando-se ao redor da colônia parasitária intracelular um halo claro, sem densidade eletrônica. É importante assinalar que nesse halo se encontram livres, componentes do citoplasma celular, em várias fases do processo lítico; as mitocôndrias são as que mais resistem à destruição sendo encontradas, com freqüência, algumas relativamente bem conservadas.
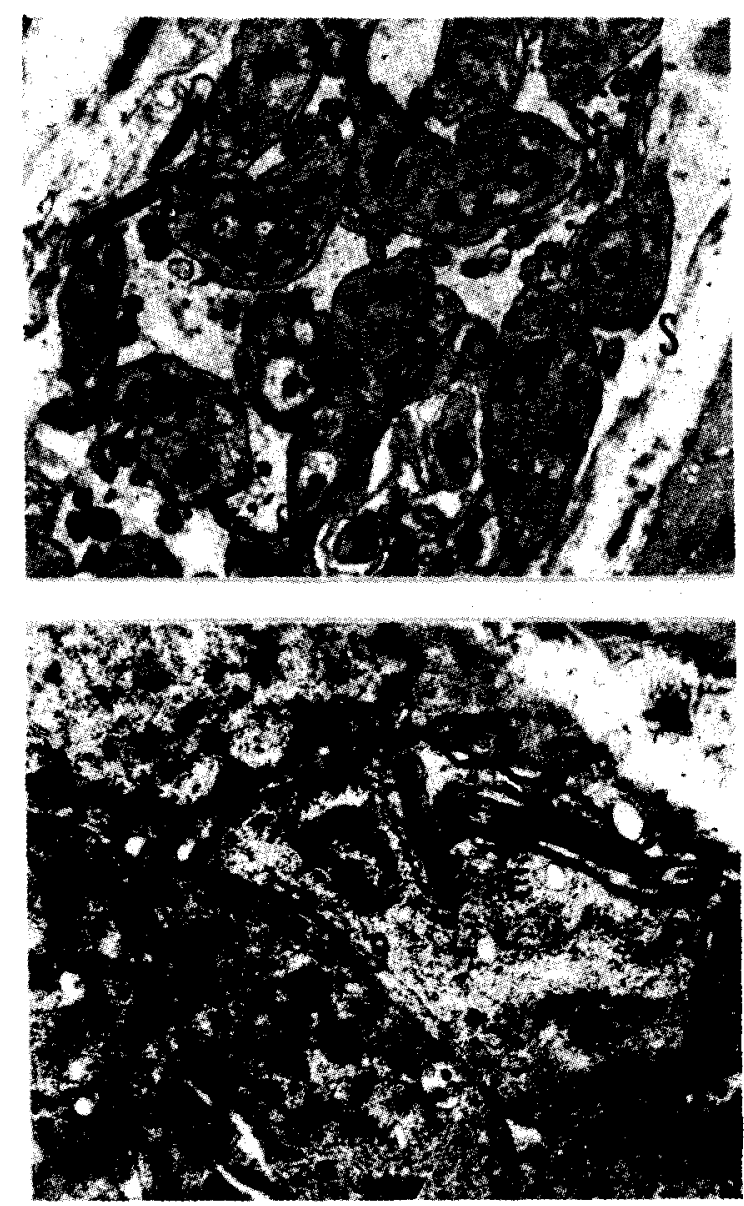

Fig. 1. A-B. Célula muscular estriada esquelética repleta de parasitos (epi-E-e tripomastigotas $-\mathrm{T}-$ ).

A. $\times 9.500 ;$ B X 17.800 
Comunicação. Ciclo intracelular do Trypanosoma cruzi e sua importância na patogênese da doença de Chagas. Tafuri WL, Chiari E, Raso P. Revista da Sociedade Brasileira de Medicina Tropical 16:219-221, Out-Dez, 1983

Agora, porém, analisando as lesões do tecido muscular esquelético de camundongos infectados com a cepa MR do $T$. cruzi e sacrificados 11 dias após a inoculação, encontramos uma dessas células musculares intensamente parasitadas e com o sarcolema rompido (Fig. 2). Praticamente todos os parasitas ainda contidos na célula, como já saidos dela eram epi e tripomastigotas íntegros (Fig. 1). Essa Fig. 2 mostra: 1) o sarcolema rompido (seta a); 2) um resquício de sarcolema ao lado de um parasita (seta b);3) parte de prováveis tripomastigotas (T) debaixo do sarcolema, entre este e o sarcoplasma; 4) entre os tripomastigotas e o sarcoplasma, aparentemente não alterados, restos de sarcoplasma incompletamente lisado.

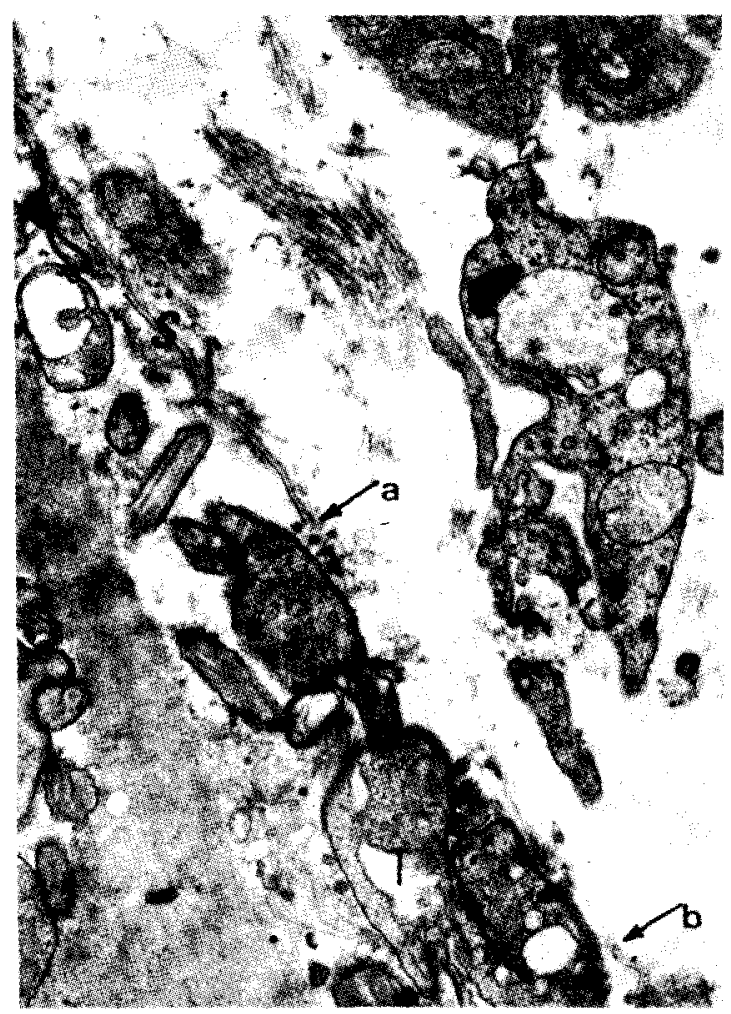

Fig. 2. Célula muscular esquelética. O momento da ruptura (setas a e b) do sarcolema (S). Parasitos cortados em vários sentidos $(T)$ sob o sarcolema. $\times 9.500$

Por sua vez, a Fig. 3, da mesma fibra muscular e do mesmo ninho de parasitas, mas de outro campo, em outra parte da célula, mostra parasitos já liberados da célula e já caídos no interstício. Mostra, ainda, que neste cairam também componentes do citoplasma da célula parasitada: mito- côndrias mais ou menos alteradas, restos do retículo endoplasmático liso e rugoso, restos de miofibrilas, partículas amorfas não identificáveis. Em suma, foi documentado um momento da ruptura da célula e da liberação dos parasitos para o interstício, que coincidiu com a transformação dos mesmos para tripomastigotas.

Além, deste fato, a observação deve ser registrada, também porque documenta o desague, no interstício, de componentes do sarcoplasma (Fig. 3); ou seja, de material auto-antigênico. Trabalhos nossos anteriores ${ }^{6}$ tinham mostrado que nem todos os amastigotas são capazes de transformarem em tripomastigotas, mas que aproximadamente $15 \%$ dos primeiros, dentro da célula hospedeira ou fora dela, degeneram; ou seja, liberam antígenos. A documentação obtida agora (Fig. 3), mostra, como aliás era óbvio, que também tripomastigotas degeneram. Desse modo, pode ser afirmado que o pool de antígenos, na tripanossomíase americana é formado por três grupos, no mínimo, de substân-

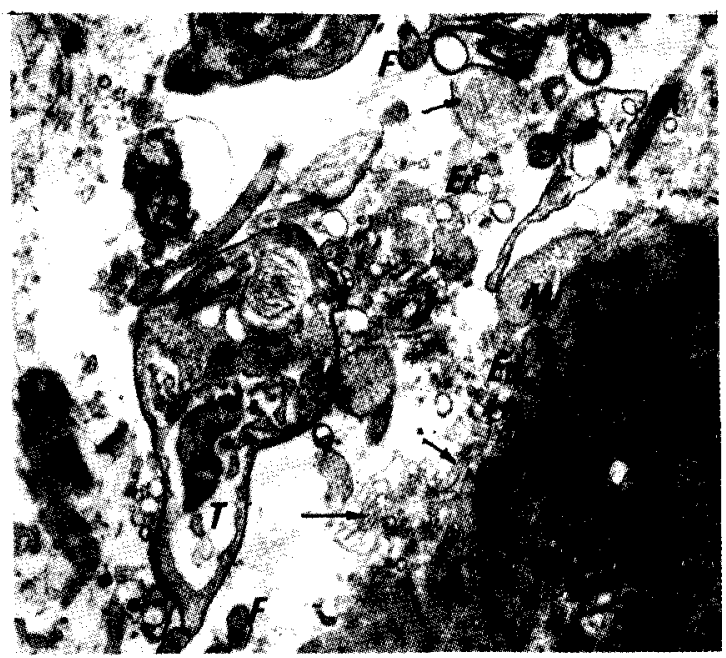

Fig. 3. Tripomastigotas (T), flagelos do parasito (F), restos de miofibrilas $(\mathrm{M})$, mitocôndrias aparentemente normais (Mi) e degeneradas (setas), restos de retículo endoplasmático, ribosomas e outras partículas amorfas no interstício bem junto da célula muscular (MC).

C. Colágeno x 20.000

cias: 1) componentes da célula parasitada e rompida; 2) componentes de amastigotas; 3 ) componentes de tripomastigotas e possivelmente de epimastigotas.

Diante de tal documentação e de acordo com dados da literatura, muitas observações indicam que do pool de antígenos que caem no inters- 
Comunicaçāo. Ciclo intracelular do Trypanosoma cruzi e sua importância na patogênese da doença de Chagas. Tafuri WL, Chiari E, Raso P. Revista da Sociedade Brasileira de Medicina Tropical 16:219-221, Out-Dez, 1983

tício muitos (do parasito ou da célula hospedeira) poderiam funcionar como imunógenos, contribuindo para explicar os fenómenos inflamatórios e destrutivos que caracterizam, em parte, a tripanossomose americana.

De fato a miocardite que se desenvolve na fase aguda e crônica da doença é, pelo menos em parte, uma imunoinflamação. Já a partir da segunda semana de infecção são notadas através da presença in situ e no soro de anticorpos IgM, IgG e IgA anti $T$. cruzi. Segundo observações de Araújo $^{1}$, confirmando nosso pensamento, todas as 3 formas de parasito induzem reaçōes imunes, com aparecimento, no soro, de duas classes de imunoglobulinas IgG e IgM.

E provável que configurações moleculares que fazem parte da estrutura das três formas do T. cruzi, bem como certos componentes da célula hospedeira que caem no interstício, no momento da ruptura da mesma sejam os responsáveis pelos mecanismos de auto-imunidade (causando dano), observada na doença de Chagas. Até $Q$ momento, ao que sabemos da literatura, foi constatada apenas a presença de anticorpos (IgM e IgG) induzidos por determinantes antigênicos do $T$. cruzi que agem tanto contra o parasito quanto contra as estruturas da célula hospedeira (membranas de neurônios centrais e periféricos, plasmalema do músculo estriado esquelético e cardíaco; membrana basal e retículo sarcoplasmático do músculo cardíaco).

\section{REFERÊNCIAS BIBLIOGRÁFICAS}

1. Araújo FG. Antigenic analysis of Trypanosoma cruzi. IX Reuniāo Anual Pesquisa Básica em doença de Chagas, Caxambú, MG, Brasil, p. 160, 1982.

2. Elkeless G. On the life cycle of Trypanosoma cruzi. I. Parasitol. 37:379-385, 1951.

3. Dvorak JA. New in vitro approach to quantitation of Trypanosoma cruzi vertebrate cell interactions. PAHO International Symposium of new approaches American Trypanosomiasis Research. Belo Horizonte, Brasil, 18 - 21 March, 1975. Pan American Health organization, p. $105-120$.

4. Meyer H, Oliveira - Musacchio MX. Cultivation of Trypanosoma cruzi in tissue cultures: A four-Year study. Parasitology 39:91-94, 1948.

5. Nogueira N, Cohn Ź. Trypanosoma cruzi: Mechanism of entry and intracellular fate in mammalian cells. Journal Experimental Medicine 143:1402 - 1470, 1976

6. Tafuri WL. Pathogenesis of lesions of the autonomic nervous system of mouse in experimental acute Chagas' disease. The American Journal of Tropical Medicine and Hygiene 19:405-417, 1970. 